\title{
Las loot boxes como modelo de monetización predatoria dentro de los videojuegos: aproximación psicoeducativa
}

\author{
Francisco Javier Sanmartín \\ Departamento de Psicología de la Universidad de Córdoba (España) \\ z82salif@uco.es | https://orcid.org/0000-0002-2870-8882 \\ Judith Velasco \\ Departamento de Psicología de la Universidad de Córdoba (España) \\ judith.velasco@uco.es | https://orcid.org/0000-0002-1887-3550
}

Susana Blanco

Gabinete de Psicología Recursos (Santiago de Compostela, España) susanablancofernandez@hotmail.com | https://orcid.org/0000-0002-3848-1159

\section{Extracto}

Las tecnologías de la información y comunicación (TIC) se han instaurado como un elemento fundamental en nuestro día a día. Sin embargo, sus beneficios se han visto empañados, con frecuencia, por los riesgos inherentes al espacio virtual. Uno de los elementos que más interés ha generado por sus implicaciones es el juego de azar online. A pesar de que su acceso se encuentra regulado, han surgido nuevas dinámicas que pretenden burlar estas restricciones emplazando mecánicas de azar en productos dirigidos a menores: hablamos de las loot boxes, un sistema de adquisición de artículos aleatorios -previo pago con dinero real- dentro de los videojuegos, cuyo funcionamiento ha sido equiparado al de las máquinas tragaperras. Aunque estas cajas se han relacionado con el consumo problemático de videojuegos y de otros juegos de azar, no se contemplan como tales en la Ley de regulación del juego en España, de manera que los menores se encuentran en una situación de desprotección ante esta problemática. Así, con el fin de visibilizar esta casuística y dotar a familias y educadores de herramientas, en el presente trabajo se aborda este fenómeno desde un triple enfoque: descriptivo, jurídico y psicoeducativo. Se proponen, desde la experiencia terapéutica y asistencial, señales de alarma con las que poder identificar un consumo de riesgo de loot boxes, así como pautas de actuación para familias y profesorado.

Palabras clave: cajas botín; juego de azar; adolescentes; videojuegos.

Fecha de entrada: 13-03-2021 / Fecha de revisión: 24-05-2021 / Fecha de aceptación: 26-05-2021

Cómo citar: Sanmartín, F. J., Velasco, J. y Blanco, S. (2021). Las loot boxes como modelo de monetización predatoria dentro de los videojuegos: aproximación psicoeducativa. Tecnología, Ciencia y Educación, 20, 103-132. https://doi.org/10.51302/tce.2021.594 


\title{
Loot boxes as predatory monetization schemes within video games: a psychoeducational approach
}

\author{
Francisco Javier Sanmartín \\ Judith Velasco \\ Susana Blanco
}

\begin{abstract}
Information and communication technologies (ICT) have become an essential part of our daily life. However, their benefits have been faded by the inherent risks of the virtual space. One of the elements that have arisen more attention is online gambling. Even though gambling is regulated and limited to adults, new dynamics aiming to overcome these restrictions have emerged by placing chance mechanics in products targeted to youth, as it is the case of loot boxes. Loot boxes are virtual chests containing random and undisclosed items that players can open following its purchase with real or in-game currencies. Being compared with slots, these mechanisms have been associated with problematic gaming and gambling. However, loot boxes are not considered a game of luck by Spanish regulations, thus placing children and adolescents in a situation of vulnerability. This study is conducted with the purpose of raising awareness of this phenomenon under a threefold perspective: descriptive, legal, and psychoeducational. In order to provide families and educators with tools to face problematic loot box consumption and to early identify risk situations, we propose -from the clinical and therapeutic practice- alarm signals and guidelines.
\end{abstract}

Keywords: loot boxes; gambling; teenagers; video games.

Citation: Sanmartín, F. J., Velasco, J. and Blanco, S. (2021). Loot boxes as predatory monetization schemes within video games: a psychoeducational approach. Tecnología, Ciencia y Educación, 20, 103-132. https://doi.org/10.51302/tce.2021.594 


\section{Sumario}

1. Introducción

1.1. Videojuegos en la vida de la población adolescente

2. Loot boxes

2.1. ¿Son las loot boxes capaces de generar adicción?

2.2. ¿Están reguladas las loot boxes? Análisis desde el ámbito legislativo

2.2.1. Ley $13 / 2011$, de 27 de mayo, de regulación del juego

2.2.2. Medidas concretas de protección contra la adicción al juego de azar (en vivo y online)

2.2.3. ¿Qué nos dicen las sentencias?

2.2.4. Otras medidas para prevenir el juego problemático en modalidad online

2.2.5. Publicidad y anuncio de juegos de azar

2.2.6. Noticias relacionadas con el consumo abusivo de loot boxes

3. Juego sostenible. El papel de la familia y el profesorado

3.1. Pautas y recomendaciones para las familias

3.1.1. Detección: señales de alarma ante las microtransacciones y las loot boxes

3.2. Pautas y recomendaciones para el profesorado

3.2.1. Prevención primaria

3.2.2. Prevención secundaria

4. Conclusiones

Referencias bibliográficas 


\section{Introducción}

El extraordinario incremento del uso de las TIC en los últimos años ha llevado a una transformación social sin precedentes en el modo de comunicarnos, interactuar y aprender. De acuerdo con el Instituto Nacional de Estadística (INE, 2019), el 80,90\% de los hogares españoles cuenta con, al menos, un ordenador, y el 91,40\%, con dispositivos con acceso a internet. Destaca la extendida presencia de las TIC, utilizadas por el 92,90\% de menores de entre 10 y 15 años. En otras palabras, una de cada tres personas que utilizan internet en el mundo es menor de 18 años (United Nations International Children's Emergency Fund [UNICEF], 2017). No obstante, la investigación actual sugiere que el calado de internet entre la generación Z (quienes nacieron entre 1994-2010) podría ser incluso mayor, al tratarse de una cohorte nacida y criada en el libre acceso a la red. En este grupo de edad, constituye un agente de socialización similar a la familia y la escuela, presente en la mayor parte de sus actividades cotidianas. De hecho, ha sido denominada «generación mobile» debido a que su desarrollo personal se ha producido de forma simultánea a la migración del uso de la red a los móviles. Vilanova y Ortega (2017) indican que el $95 \%$ de la generación Z tiene smartphone y que casi el $40 \%$ pasa entre 6 y 10 horas conectada. Todos estos indicadores apuntan a la necesidad de adaptar los contenidos analógicos al nuevo mundo digital, en tanto que este permite aunar dos elementos fundamentales: las ventajas y facilidades que brinda la tecnología y los beneficios de trabajar en un espacio atractivo para la juventud (Hernández, 2019). La presencia de las TIC en el contexto escolar es ya una realidad en los centros educativos. Según el informe de la Organización de Estados Iberoamericanos para la Educación, la Ciencia y la Cultura (OEI) y la Fundación Telefónica (2018), el 66 \% del alumnado emplea las TIC para hacer deberes y un $97 \%$ del profesorado contempla su uso en los planes docentes. Así, la proliferación de iniciativas como la digitalización de los contenidos académicos y la gamificación son un reflejo de la utilidad de la tecnología para fomentar la adquisición del conocimiento a través de estrategias más accesibles y amigables para la niñez y adolescencia.

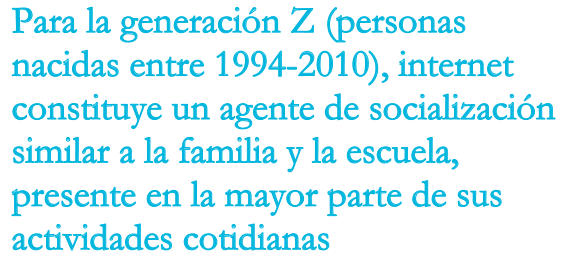

Para la generación Z (personas nacidas entre 1994-2010), internet constituye un agente de socialización similar a la familia y la escuela, presente en la mayor parte de sus actividades cotidianas

Sin embargo, el incontestable valor de las TIC se ha visto empañado por la existencia de ciertos riesgos propiciados por las características de internet y la dificultad para mantenernos actualizados ante su rápida evolución. Si bien es cierto que cada vez son más frecuentes las iniciativas que pretenden derribar la brecha entre nativos e inmigrantes digitales, esta labor entraña una gran complejidad debido a que -añadidas a la importación al medio virtual de problemáticas cotidianas en la vida de los menores (por ejemplo, acoso escolar)- el rápido avance de la tecnología ha motivado la aparición de nuevas amenazas (por ejemplo, grooming, 
sextorsión, etc.), haciendo del ciberespacio un entorno en transformación constante. La instauración de las TIC como espacio de relación normativo ha dado lugar a nuevos desafíos para los profesionales que trabajan con esta población, como, por ejemplo, el uso abusivo de internet. El interés clínico por la inadecuada utilización de la tecnología ha motivado, incluso, la creación de la categoría diagnóstica «trastorno por uso de videojuegos» en la CIE-111 (Organización Mundial de la Salud [OMS], 2018). Otro ejemplo que ilustra la irrupción de la tecnología en el ocio de la juventud se encuentra en la elevada implicación de esta en el ámbito de las apuestas online. Aunque existe una normativa cuyo objeto es reducir su impacto en los menores (Ley 13/2011, de 27 de mayo, de regulación del juego), hay multitud de opciones de acceso que no requieren la presencia física del menor en los establecimientos. Así, la facilidad con la que niños, niñas y adolescentes pueden usar dispositivos con internet, unido a las laxas medidas de seguridad que estas plataformas emplean para limitar su acceso exclusivamente a personas adultas, dan lugar a una situación de riesgo que puede incentivar el juego problemático en los jóvenes. Tal y como se mencionó, uno de los elementos que caracteriza a las TIC es su rápida evolución. Este aspecto constituye un arma de doble filo en el contexto del juego en tanto que, a la vez que ofrece una experiencia más dinámica y entretenida al usuario, obstaculiza el control adulto y facilita el acceso de los menores a contenidos inapropiados para su nivel de desarrollo cognitivo y psicoemocional. En este escenario se insinúa una batalla velada entre las empresas que se lucran con este modelo de negocio y las entidades responsables de la regulación, que se evidencia en la competición por desarrollar mecánicas que generen interés en los usuarios y que no estén contempladas en la legislación, y la rápida actualización y modificación de esta para dar una respuesta a las nuevas formas de juego. Un ejemplo de dinámica que emplaza juegos de azar en productos ampliamente utilizados por menores se encuentra en las denominadas loot boxes o cajas botín, un mecanismo dentro de los videojuegos que ofrece, previo pago, un objeto «aleatorio» al usuario. Se ha descrito la posible relación de la apertura de estas cajas con el consumo de otras formas de azar (Zendle y Cairns, 2019). Resulta esencial que familias y profesorado conozcan su existencia para desarrollar estrategias conjuntas y coordinadas que fomenten un consumo sostenible y responsable.

\subsection{Videojuegos en la vida de la población adolescente}

Los videojuegos se encuentran muy presentes entre la población adolescente (Holtz y Appel, 2011), con casi un 80 \% de usuarios que juega habitualmente (León-Jariego y LópezLópez, 2003). Si bien es cierto que los videojuegos han estado tradicionalmente vinculados al estereotipo nerd, esta idea se encuentra muy alejada de la realidad. De hecho, según la Asociación Española de Videojuegos (AEVI, 2019), en nuestro país, el $42 \%$ de las personas de entre 6 y 64 años hacen uso de ellos, lo que representa, aproximadamente, 15 millones

1 Clasificación Internacional de las Enfermedades. 
de jugadores. Esta forma de ocio resulta, además, muy rentable, alcanzando 43,4 billones en beneficios en 2018, con un número de usuarios, solo en EE. UU., que supera los 164 millones (Entertainment Software Association, 2018). En España, la AEVI (2019) señala que, en 2019, los videojuegos generaron 1.479 millones de euros, el equivalente al $0,11 \%$ del producto interior bruto (PIB), siendo la primera opción de ocio audiovisual y cultural en nuestro país, por encima de la música y el cine. De este modo, los videojuegos parecen ser una parte fundamental del ocio juvenil. Además de ser una manera de divertirse y distraerse, se han señalado otras razones para su uso. Primero, son un medio para relacionarse fuera del contexto escolar (Gil et al., 2020; Marín y García, 2005) que permite fortalecer los vínculos interpersonales (Lenhart, 2015). Segundo, posibilitan una evasión temporal a un mundo de fantasía (Greenberg et al., 2010) en el que es posible interactuar con objetos, personajes y realidades ajenas y, por tanto, descubrir nuevas experiencias y distanciarse de lo cotidiano (Schwartz, 2006). Finalmente, también permiten poner a prueba las propias habilidades y compararse con otras personas en los modos competitivos y online (Vorderer et al., 2003). Además de todo lo anterior, los videojuegos pueden tener un impacto positivo a nivel psicológico/cognitivo: desarrollo de habilidades visoespaciales (Del Moral-Pérez et al., 2015); aprendizaje y creatividad (Eguia et al., 2013); promoción de la actividad física (Ruiz-Ariza et al., 2018); conductas prosociales, relaciones interpersonales y regulación emocional (Greitemeyer y Mügge, 2014; Sánchez-Rodríguez et al., 2010; Villani et al., 2018); y potenciación de habilidades cognitivas (Dye et al., 2010, McDermott et al., 2014; Parong et al., 2017).

Sin embargo, también se han documentado efectos negativos como la agresividad. Aunque existen videojuegos que premian la prosocialidad, muchos incluyen contenidos violentos que pueden promover conductas y pensamientos agresivos (Greitemeyer y Mügge, 2014) e insensibilización hacia la violencia. Adicionalmente, quienes hacen un uso abusivo pueden presentar dificultades de concentración, alteraciones de sueño y menor rendimiento académico. Igualmente, aunque los videojuegos, por sí mismos, no incitan al aislamiento, pueden llevar a una reducción de interacción social en el medio físico. Finalmente, destaca su potencial adictivo por los efectos que causan en quien los juega: son divertidos, atractivos y competitivos (Ledo et al. , 2016), especialmente los juegos online (Lemmens y Hendriks, 2016) por el tipo de refuerzo: intermitente y de valor (Griffiths y Beranuy, 2009). Un elemento presente en los videojuegos online, en el que este tipo de reforzamiento se hace especialmente patente, son las loot boxes, donde la población infanto-juvenil se encuentra altamente expuesta.

\section{Loot boxes}

Las loot boxes (cajas botín o de recompensa) son un mecanismo que se ofrece dentro de algunos videojuegos por el que los jugadores obtienen objetos «aleatorios» tras su adquisición. Estos ítems pueden ser esenciales para progresar en el videojuego o cosméticos (Brady y Prentice, 2019). 
La característica esencial de las loot boxes es su naturaleza aleatoria, responsable de su semejanza con los juegos de azar y que, en último término, le conferiría su potencial adictivo. Es posible obtener estas cajas de dos maneras: durante el juego, a modo de recompensa, y/o mediante una transacción económica, con dinero real o con monedas propias del videojuego, de carácter virtual, pero que han de ser adquiridas, generalmente, con dinero real. Las cajas botín son el sistema de monetización preferente en los videojuegos gratuitos como Clash Royale o Hearthstone, pero también es posible encontrarlos en videojuegos triple A (Drummond et al., 2019), entre ellos, FIFA20 Ultimate Team o NBA2K20. Aunque en la mayoría de los casos estas cajas se consiguen dentro de los juegos, existen webs donde es posible probar suerte mediante su compra, cuyo contenido podrá transferirse posteriormente al juego. En algunas páginas se pueden incluso diseñar cajas botín personalizadas, siendo el usuario quien selecciona los artículos que desea. El coste de la caja, no obstante, estará sujeto al valor de las recompensas (por ejemplo, el precio será mayor si se incluyen videojuegos u objetos valiosos). Así, si el usuario quiere una caja asequible económicamente, deberá incluir mayor cantidad de artículos de escaso valor, incrementando la probabilidad de que no le toque el elemento que deseaba inicialmente y que obtenga otro de valor inferior al invertido.

Los ítems obtenidos en las cajas suelen seguir una jerarquía por colores. En juegos como Overwatch o Hearthstone, los objetos se categorizan como comunes (blancos), poco comunes (azules), épicos (morados) y legendarios (dorados). Estos artículos, en ciertas ocasiones, pueden ser tradeables (Abarbanel, 2018), es decir, intercambiables con otros jugadores, o bien pueden ser vendidos, dentro del propio sistema del videojuego o a través de terceros. Sirva para ilustrar esta cuestión los historiales de ventas que proporcionan webs como DMarket, donde se observa que, en relación con el videojuego Counter Strike Global Offensive, 20 usuarios adquirieron el ítem «guantes de especialista», con un coste de 353,57 \$ (aproximadamente, $296 €$ ) entre febrero y abril de 2020. En la misma línea, la web U7BUY permite adquirir jugadores del FIFA20, como Pelé $(1.028,90 €)$, Maradona $(364,79 €)$ o Ronaldo $(1.633,29 €)$, por lo que existen ciertos objetos que van a ser más codiciados que otros, ya sea por sus implicaciones o valor dentro del juego (por ejemplo, incrementar las posibilidades de ganar, prestigio, etc.) o por su cotización.

Como se indicó anteriormente, a las loot boxes están expuestos, principalmente, adolescentes y adultos jóvenes; población que, según la literatura, podría ser más vulnerable a desarrollar conductas de juego problemático (Zendle et al., 2019). No obstante, también pueden estar orientadas a otros grupos de edad, como la infancia (McCaffrey, 2019) y la adultez (Zendle y Cairns,
A las loot boxes están expuestos, principalmente, adolescentes y adultos jóvenes; población que, según la literatura, podría ser más vulnerable a desarrollar conductas de juego problemático 
2018, 2019), dependiendo de la temática de cada videojuego. En lo tocante a la adolescencia, estudios actuales apuntan a que cada vez se encuentra más distanciada de las formas tradicionales de juegos de azar (Gainsbury, 2019), prefiriendo hacer uso de las TIC para ello. Diversas razones subyacen a esta cuestión, entre ellas: la facilidad operativa y de acceso, la posibilidad de evitar el estigma asociado al hecho de acudir físicamente a las casas de apuestas y la normalización de este fenómeno como actividad de ocio juvenil (Megías, 2020). Estos elementos podrían dar cuenta de la proliferación de las loot boxes, puesto que son un método novedoso, integrado de modo natural dentro de los videojuegos y que, siendo una forma de juego de azar, se encuentra alejado de las implicaciones sociales negativas del mismo.

Aproximadamente la mitad de los adolescentes conocen la posibilidad de adquirir loot boxes (United Kingdom Gambling Commission, 2018) y, entre el $31 \%$ y el $50 \%$, ya lo habría hecho (Kristiansen y Severin, 2020). El valor de estas cajas es reconocido por los más jóvenes, quienes destacan como motivos para su adquisición la obtención de ventajas dentro del juego, la consecución de un ítem específico, completar la colección o la excitación experimentada en el momento de abrirlas (Zendle et al., 2019). Es importante entender que las loot boxes comparten diversas características con las formas de juego tradicional en lo que a su presentación se refiere. Además de poder encontrarse con distintas formas, se incluyen multitud de estímulos para incrementar su atractivo: efectos sonoros, colores y luces intermitentes que hacen de la apertura de la loot box un espectáculo audiovisual. No en vano, algunos autores, como Derevensky y Griffiths (2019), señalan el paralelismo entre las loot boxes y las máquinas tragaperras, añadiendo a lo anterior la distribución aleatoria de los premios, los cuasiaciertos o near-misses (Zendle et al., 2020) y el no requerimiento de habilidad para jugarlo (King y Delfabbro, 2019b). Todo ello, unido a la excitación que genera la incertidumbre por el objeto que se espera obtener y las implicaciones que ello conlleva a nivel social en la comunidad gamer, constituyen un caldo de cultivo para una sutil e insidiosa instauración de conductas de juego de azar, comenzando por la normalización y desestigmatización por parte del usuario. Actualmente, la investigación está relacionando las loot boxes con las conductas de juego problemático desde dos paradigmas: como juegos de azar (Drummond y Sauer, 2018) y como adicción a los videojuegos
Hay algunos autores que señalan un paralelismo entre las loot boxes y las máquinas tragaperras
La excitación que genera la incertidumbre por el objeto que se espera obtener y las implicaciones que ello conlleva a nivel social en la comunidad gamer constituyen un caldo de cultivo para una sutil e insidiosa instauración de conductas de juego de azar 
(King y Delfabbro, 2019a). Esta cuestión se recoge en investigaciones como las de Li et al. (2019), Meduna et al. (2019) o Drummond et al. (2020), en las que se encuentra que los jugadores más involucrados con las loot boxes hacen mayor uso de otros juegos de azar (póker, tragaperras, apuestas deportivas, etc.) y presentan mayor nivel de adicción a videojuegos. Es interesante señalar que esta faceta de las loot boxes no es desconocida para quien juega. De facto, en torno al $80 \%$ las reconoce como una forma de apuesta o juego de azar (Brooks y Clark, 2019). Sin embargo, esta cuestión no parece tener una incidencia directa en su consumo.

Por otro lado, atendiendo al gasto en loot boxes en población adulta, Zendle y Cairns (2018) encontraron que los que presentaban conductas de juego problemático en relación con las apuestas invertían significativamente más dinero en loot boxes al mes $(5,42 €)^{2}$ que aquellos sin dicho historial $(2 €)$. Posteriormente, los autores replicaron el estudio, encontrando la misma tendencia de gasto según el perfil del jugador, pero con un incremento del consumo en todos los participantes. Resulta de especial interés que este mismo patrón parece reproducirse en los adolescentes (Zendle et al., 2019). Concretando su gasto, quienes no tenían problemas con el juego de azar invertían un promedio de 20,88 euros al mes, los que presentaban un riesgo moderado-alto gastaban 36,63 euros y aquellos cuya conducta podía ser etiquetada como problemática gastaban 70,93 euros. Tal y como especifican Zendle y Cairns (2018), debido a la escasez de estudios longitudinales, resulta difícil esclarecer si la compra de loot boxes incita al juego de azar o si son los jugadores con rasgos de juego problemático quienes más compran loot boxes. No obstante, al igual que estos autores, consideramos que ambas perspectivas son convergentes.

Todo lo expuesto hace referencia, en su mayoría, a investigaciones realizadas con personas adultas. Sin embargo, es importante tener en cuenta que muchos de los videojuegos que contienen loot boxes son accesibles para la población infantil. Drummond y Sauer (2018) analizaron 22 videojuegos que contenían loot boxes, siguiendo los parámetros de la edad recomendada según el Entertaiment Software Ratings Board (ESRB) y los criterios del juego de azar propuestos por Griffiths (1995). Aproximadamente el $45 \%$ cumplía todos los criterios y, de estos, 6 estaban calificados para adolescentes de 13 años o menos. En la misma línea, Zendle et al. (2020) analizaron los más populares dentro del market de Android, encontrando que el $56 \%$ de los videojuegos de Android e iPhone contenían loot boxes y el $36 \%$ de Steam ${ }^{3}$.

2 En la investigación original, el gasto en loot boxes se expresa en dólares americanos. Se ha transformado el gasto a euros para facilitar la lectura y comprensión de la inversión de los usuarios en las cajas botín.

3 Plataforma de distribución digital de videojuegos. 
En torno al $95 \%$ de los videojuegos de móvil que incluyen loot boxes son calificados como apropiados para usuarios a partir de 12 años. Considerando que la población infantil y adolescente no cuenta con un desarrollo pleno de sus capacidades cognitivas y, concretamente, aquellas relacionadas con el control de impulsos, el emplazamiento de este tipo de objetos en productos para menores constituye un ejercicio de dudosa ética (Neely, 2019; Zendle y Bowden-Jones, 2019). Además del nivel de desarrollo cognitivo, psicológico y emocional de los menores, se sintetizan ciertos elementos que pivotan alrededor de las loot boxes incrementando su atractivo e instigando a su consumo:

- Inclusión de loot boxes cebo. Se le regalan al usuario cajas para que las pruebe, proporcionándole objetos que pueden llevarle a adquirir más.

- Bajo coste. El pago de estas cajas suele ser de pequeñas cantidades, por lo que la percepción de pérdida del jugador es mínima.

- Introducción de cuasiaciertos (near-misses). Al jugador se le muestran elementos de valor cerca del artículo que le ha tocado, con el fin de generar la ilusión de que está cerca de conseguir lo que desea y que vuelva a intentarlo.

- Adaptación de las cajas al interés del jugador. Las cajas pueden variar de unos videojuegos a otros, tanto en colores como en formas y sonidos, haciendo la experiencia mucho más excitante (McCaffrey, 2019).

- Utilización de monedas virtuales. El pago con monedas propias de videojuegos lleva a la apreciación de que la cantidad de dinero gastada es menor. Esta práctica se ha asociado a una mayor implicación en el juego de azar (Zendle, Meyer et al., 2020).

- Diseño de campañas y sensación de exclusividad de los objetos. La inclusión de artículos únicos que solo estarán presentes por tiempo limitado puede generar una sensación de necesidad en el usuario (King y Delfabbro, 2019b), si bien se han encontrado resultados contradictorios (Zendle, Meyer et al., 2020).

- Monetización de los artículos. Aproximadamente, un tercio de los participantes compradores de loot boxes refirieron haber vendido los ítems que les habían tocado (Brooks y Clark, 2019). La venta es un factor que se asocia, en mayor medida, con el juego de azar (Kristiansen y Severin, 2020; Zendle et al., 2020), puesto que la visión de la apertura de cajas cambia hacia una más monetaria, no tanto de diversión.
Observar a creadores de contenido invertir en loot boxes podría favorecer el consumo de estas cajas, creando una impresión sesgada de la probabilidad de obtener el artículo deseado 
- Influencia de los streamers. Observar a creadores de contenido invertir en loot boxes podría favorecer el consumo de estas cajas, creando una impresión sesgada de la probabilidad de obtener el artículo deseado, si bien la investigación ha arrojado resultados inconsistentes. Así, Macey y Hamari (2019) encontraron una relación inversa entre la visualización de esports (deportes electrónicos) y el consumo de loot boxes, atribuyéndolo a una mayor sensibilidad de los jugadores sobre los aspectos negativos de estas; por su parte, Meduna et al. (2019) hallaron que los que apuestan en este tipo de plataformas tienden a una mayor compra.

Pese a la proliferación de estrategias para generar la necesidad psicológica de adquisición de estas cajas en menores, es importante señalar que existen organismos cuya misión es valorar el contenido de los videojuegos (por ejemplo, lenguaje, violencia, sexo, drogas, etc.) y determinar una edad adecuada para su consumo. Entre ellos, se encuentran la ESRB en América y el Pan European Game Information (PEGI) en Europa. No obstante, la rápida evolución de la tecnología y las nuevas dinámicas incluidas en los videojuegos han tenido como resultado que, hasta 2020 , no se hayan contemplado las compras dentro de estos entre sus categorías. Actualmente, existe el descriptor «incluye compras», pero no se especifica la naturaleza de estas (por ejemplo, loot boxes, niveles extras, pases de batalla, monedas virtuales, etc.).

\section{1. ¿Son las loot boxes capaces de generar adicción?}

En este punto, todo parece indicar que las loot boxes son sistemas capaces de generar una adicción psicológica y conductual: su presentación, los reforzadores, las emociones que producen, etc. Pero ¿satisfacen los criterios clínicos para considerarlas una adicción?

Según Echeburúa (1999), todas las conductas con potencial adictivo se instauran, inicialmente, por su capacidad para provocar placer (en este caso: excitación al abrir la caja, emoción por el resultado, beneficios sociales de tener un ítem único en el grupo de iguales, etc.), pero, posteriormente, se mantienen por la necesidad de aliviar los sentimientos negativos que se producen si no se consume (por ejemplo, inquietud, necesidad de abrir cajas, etc.). De esta manera, se establece un patrón de conducta en el que se actúa sin control, incluso cuando se es consciente del impacto negativo en nuestra vida. Para que podamos hablar de adicción, es necesario que exista un síndrome de abstinencia caracterizado por los elementos listados a continuación y que hemos adaptado a las loot boxes:

- Impulso en forma de deseo intenso por realizar la conducta incluso cuando genera consecuencias negativas. Aunque las probabilidades de conseguir el objeto deseado son pocas (Griffiths, 2018), su sistema de refuerzo genera la ilusión de tener posibilidades reales de ganar. Este criterio puede ser difícil de identificar inicialmente en las cajas, por su bajo coste (por ejemplo, $1 €$ ). 
- Tensión creciente hasta la ejecución de la conducta. Los jugadores experimentan una activación fisiológica antes de abrir las loot boxes. Brady y Prentice (2019) encontraron un aumento de la respuesta galvánica de la piel ante la apertura y Larche et al. (2019), un incremento de la conductancia dérmica y la activación (arousal) en función del valor de las cajas. Esta tensión podría reducirse mediante una apertura vicaria, es decir, viendo a otros abrir cajas (por ejemplo, youtubers).

- Desaparición temporal de la tensión tras abrir la caja. La apertura de las loot boxes reduce la necesidad psicológica o craving, diminuyendo, por tanto, la sintomatología física asociada y produciendo una sensación temporal de bienestar.

- Vuelta gradual del impulso asociado a estímulos internos (aburrimiento, recordar el placer experimentado anteriormente) y externos (visión del objeto de deseo). Los jugadores que siguen a creadores de contenido se encuentran altamente expuestos a la apertura de cajas botín, un proceso que, además, se presenta de forma enaltecida como un evento de gran interés. Los youtubers se exhiben invirtiendo grandes cantidades de dinero y obteniendo artículos únicos, lo que contribuye a la necesidad de emularlos. Siguiendo a Labrador (2013) en relación al juego patológico general, y aplicándolo a nuestro objeto de estudio, observar que otros usuarios obtienen los artículos deseados puede incentivar el consumo.

Las loot boxes parecen satisfacer estos criterios, de modo que, a nivel clínico, podríamos vincularlas con la conducta de juego problemático. No obstante, su identificación temprana puede ser compleja debido a sus propias características.

Así, la transición de juego normal a patológico se ha concebido, tradicionalmente, en función de tres indicadores (Echeburúa, 1999, p. 31):

- Incremento del gasto inicialmente planteado.

- Invertir más dinero para recuperar las pérdidas.

- Seguir jugando pese a las pérdidas.

El coste habitual de las loot boxes suele ser bajo, de manera que el jugador puede ver mermada su capacidad para identificar el sobrecoste de su inversión. Además, es frecuente la incorporación de mecanismos como los near-misses que generan en la persona la ilusión de encontrarse cerca del premio.

Así, se dibuja un escenario en el que encontramos a un usuario que siempre está «a punto» de obtener un ítem de gran valor invirtiendo una escasa cantidad de dinero, repitiendo la conducta una y otra vez. 


\section{2. ¿Están reguladas las loot boxes? Análisis desde el ámbito legislativo}

La literatura advierte de las similitudes entre las loot boxes y los juegos de azar, compartiendo mecanismos, estrategias e, incluso, efectos psicofisiológicos. Por ello, plantearemos brevemente un análisis del fenómeno desde la óptica legislativa española actual sobre recreativos de alea o azar que pudieran ser de aplicación a este nuevo fenómeno en aras de orientar a los progenitores y, en último término, garantizar la protección de la infancia.

\subsubsection{Ley 13/2011, de 27 de mayo, de regulación del juego}

En España, el juego de azar se regula conforme a la Ley 13/2011, que establece, en su artículo 6, una serie de prohibiciones encaminadas a promover un juego seguro y limitar las posibles consecuencias negativas que pudieran derivarse de una conducta problemática, siendo las más relevantes en el análisis de las loot boxes las siguientes:

- Prohibición de toda actividad que atente contra la dignidad, el derecho al honor, a la intimidad personal, a la propia imagen, contra los derechos de la juventud y de la infancia, etc.

- Prohibición de toda actividad que se fundamente en la comisión de delitos, faltas o infracciones administrativas o que recaiga sobre eventos prohibidos.

- Se prohíbe la participación de los menores de edad, de los incapacitados legalmente, de las personas que lo tengan prohibido por resolución judicial o de las que lo hayan solicitado voluntariamente (apdo. ilustrado posteriormente con sentencias).

Las infracciones por la vulneración de dicho articulado se categorizan en muy graves (art. 39), graves (art. 40) y leves (art. 41). Entre las graves encontramos las siguientes: permitir el acceso a las personas que lo tienen prohibido, la concesión de préstamos/créditos por parte de los operadores, realizar promoción de la actividad infringiendo parámetros legales o la negativa reiterada de los organizadores a facilitar información requerida por la Comisión Nacional del Juego. Las sanciones fluctúan entre apercibimiento o multa de hasta 100.000 euros para infracciones leves; de 100.000 a 1.000 .000 de euros y suspensión de la actividad en España por un máximo de seis meses para las graves; llegando a multas de entre 1.000 .000 y 50.000 .000 de euros a través del Ministerio de Economía y Hacienda o la inhabilitación por un periodo máximo de cuatro años. El número de sanciones impuestas por vulnerar tales artículos resulta, grosso modo, bajo. En el año 2014 se computaron doce infracciones del artículo 40 b) (permitir acceso a personas que lo tienen prohibido), dos en el año 2018 y nueve en 2019. Respecto a la difusión de publicidad o patrocinio fuera de los márgenes legales (art. 40 d), se contabilizaron dos casos en 2014, cuatro en 2015, tres en 2016 y uno en 2017, 2018 y 2019. Todos los elementos descritos anteriormente podrían ser aplicados al funcionamiento de las cajas botín (por ejemplo, acceso de los menores a las mismas, celebridades prestando su imagen para incentivar su consumo, etc.), si bien, en el momento actual, esta ley no las contempla. 


\subsubsection{Medidas concretas de protección contra la adicción al juego de azar (en vivo y online)}

Dada la preocupación por las consecuencias perniciosas del juego problemático, se han creado entidades y medidas que intentan paliarlas. Entre ellas, la Dirección General de Ordenación del Juego, el Consejo Asesor de Juego Responsable o el Registro General de Interdicciones de Acceso al Juego (RGIAJ). Este registro público, creado en virtud de la Ley 13/2011, posibilita la autoprohibición al juego, donde los propios jugadores pueden solicitar, voluntariamente, el ingreso en estas listas para que se vete su acceso a centros/ webs que puedan incentivar o disparar su conducta de juego. No obstante, la inclusión en dicha lista también puede estar dictada judicialmente. Con todo, la medida es aplicable a las formas de juego tradicionales, no encontrándose una alternativa extrapolable a las loot boxes. Además, algunas plataformas de juego online presentan medidas de identificación laxas, lo que permite que cualquier usuario las use con nickname, criptomonedas, etc., con independencia de su edad o la existencia de restricciones terapéuticas o jurídicas.

\subsection{3. ¿Qué nos dicen las sentencias?}

Tanto para dar a conocer las consecuencias más disfuncionales del juego problemático como para dibujar las características que confluyen en los procesos que terminan en los juzgados, las sentencias se revelan como un instrumento de suma utilidad. Así, tras un somero examen de las que incluían los descriptores «incapacitación», «ludopatía» y términos asociados al Registro General de Interdicciones de Acceso al Juego (RGIAJ), apreciamos que algunas recogían la privación del derecho de sufragio, de permisos de armas e incluso del de conducir; pero no hemos encontrado ninguna que incluyera el mandato de ser inscrito en dicho registro. Además, en un alto porcentaje de las sentencias existía evidencia de patología dual (persona que presenta simultáneamente una dependencia y un desorden psicológico), señalando la literatura que llega a alcanzar el 80 \% (Torrens, 2008). A continuación, se exponen algunos ejemplos:

- Esquizofrenia. Sentencia 616/2017 de la Audiencia Provincial de Barcelona: «La falta de tratamiento de su esquizofrenia paranoide, de la que no parece consciente, su tórpida evolución complicada por la ludopatía y el consumo de tóxicos (alcohol y cocaína) lo coloca en una situación de grave peligro»; fallando que «padece una enfermedad psíquica que le inhabilita en el orden patrimonial para la administración de bienes y toma de decisiones personales que excedan de las ordinarias [...] deberá quedar sometido a tutela».

- Trastorno ansioso-depresivo. Sentencia 334/2014 del Tribunal Superior de Justicia de Castilla-La Mancha: «Presenta ludopatía y depresión, con mala adherencia al tratamiento, [...] en un intento anterior de revisión, se concretaba un trastorno de ansiedad generalizada, distimia y ludopatía, declarando que continúa bajo situación de incapacidad permanente absoluta». 
- Trastornos de personalidad. Sentencia 153/2016 de la Audiencia Provincial de Valencia: «Afectado por trastorno explosivo de la personalidad, juego patológico con dependencia grave a juegos de azar, alteraciones de conducta e intentos autolíticos [...]. Incapacitación para tomar decisiones económicas (podrá disponer de $200 €$ mensuales), para consentir tratamiento para conducir vehículos, armas o tenencia de animales peligrosos».

- Discapacidad intelectual. Sentencia 188/2012 del Tribunal Superior de Justicia de La Rioja: «Retraso intelectual secundario a patología perinatal, inteligencia límite y alteración de la conducta y control de impulsos, heteroagresividad, y minusvalía del $39 \%$. Ludopatía tratada desde 2007, por lo cual ha sido declarado judicialmente incapacitado parcialmente para regir sus bienes y patrimonio, y sometido a curatela. En la consideración del Equipo de Valoración de Incapacidades (EVI) se constata: limitación para trabajos que requieran el manejo de grandes sumas de dinero o la permanencia en lugares donde haya juegos de azar».

Entendemos que el hecho de que las sentencias aludan a procesos psicopatológicos severos obedece a que solo los casos más graves llegan a los estamentos judiciales; destacando la constante alusión a la falta de conciencia de enfermedad y a la carencia en el control de impulsos, cuestión que afectaba obviamente al gasto en juegos, dado su carácter impulsivo. En las sentencias que incluían el descriptor «RGIAJ» observamos que las denuncias eran interpuestas por personas que, estando inscritas en el mismo, habían solicitado el cobro del premio, siéndole este denegado por su condición de figurante en la lista. Esta cuestión nos plantea la disyuntiva de que, en ocasiones, el control solicitado a través de la inclusión en el registro no ofrece una protección efectiva, puesto que los usuarios accedían a la compra de boletos, llegaban a entrar en salas de juegos e incluso participaban en sorteos de televisión mediante SMS (a pesar de la advertencia en las bases sobre estar inscritos en el RGIAJ). Así, las personas demandantes que pretendían realizar el cobro alegaban que los boletos se los habían regalado o comprado terceras personas. Aun así, todas las sentencias desestimaban las pretensiones de los figurantes en el RGIAJ. Otra casuística encontrada giraba en torno a los fallos que condenaban a las empresas de juego al pago de multas por permitir jugar a menores y a personas inscritas en el RGIAJ (infracción grave, art. 40 b) de la Ley 13/2011), ascendiendo el importe a 169.805 euros (Sentencia 267/2017 del Tribunal Superior de Justicia).

Lo expuesto pone de relieve la escasa efectividad de este registro como método único para disuadir a los usuarios del consumo de juegos de azar, siendo una herramienta que puede emplearse de modo complementario en el marco de una intervención terapéutica. En el caso que nos ocupa, las loot boxes, no existen registros similares, siendo posible que los usuarios accedan a estas plataformas incluso ante la existencia de problemas asociados al juego. En plataformas autorizadas por el Gobierno de España, la identidad de los participantes es verificada mediante los mecanismos establecidos por la Ley 13/2011 y por la Dirección General de Ordenación del Juego para garantizar que todos sean mayores de 18 años, sin embargo, en la compra de loot boxes, los jugadores pueden crear cuentas empleando distintos correos electrónicos y utilizando tarjetas de prepago que se pueden adquirir en multitud de establecimientos habituales sin necesidad de revelar aspectos de su identidad como la edad. 


\subsubsection{Otras medidas para prevenir el juego problemático en modalidad online}

Existe la solicitud de autoexclusión temporal (desde un mes, un año o indefinida), el test de autoevaluación de juego responsable (requisito indispensable en caso de querer aumentar el límite impuesto para las apuestas) y la posibilidad de restringir el depósito de fondos, en el que, de no hacerlo personalmente, se establecen por defecto cuantías que no permiten superar los 600 euros por día, los 1.500 euros por semana y los 3.000 euros por mes. Además, las páginas de juegos deben contener información sobre centros que ofrecen ayuda para jugadores problemáticos; el acceso a la última sesión, el dinero invertido, el tiempo empleado, la hora actual, etc., todo ello para evitar la pérdida de noción de tiempo que se produce a menudo cuando alguien está inmerso en estas situaciones. Estas medidas de apoyo no se contemplan para las compañías de videojuegos, puesto que las loot boxes no se reconocen como juegos de azar. Si la ley las calificara como instigadoras del juego de azar, sería de obligado cumplimiento interponer estrategias preventivas que redujeran el consumo entre los menores.

En conclusión, todavía no se han establecido medidas legislativas específicas en España respecto a las loot boxes; sin embargo, otros países sí han tomado cartas en el asunto. Bélgica las ha prohibido, contemplando multas de elevada cuantía para los videojuegos que las incluyan. Sus motivaciones radican en que el informe de la comisión de estudio encontró que las recompensas de las cajas son inciertas, pudiendo dar lugar a reacciones emocionales adversas, y de algún modo los jugadores son engañados, ya que no existe normativa alguna que les proteja, equiparándolas, además, a juegos de azar. Medidas similares han adoptado los Países Bajos y Corea del Sur. Alemania aboga por la prohibición y por realizar una clasificación por edades, atendiendo a toda la normativa vigente.

En otro extremo se encuentran EE. UU. y Reino Unido, quienes sustentan que las cajas botín no pueden considerarse apuestas porque siempre se recibe premio, y estos son de uso exclusivo en el juego (De Mendizábal, 2018; Sanz, 2018).

Por otra parte, en cuanto al tiempo invertido en el uso de videojuegos, China, ya en 2018 , anunció medidas para regular las horas dedicadas a los videojuegos debido a estudios que señalaban los efectos adversos del uso intensivo, como el aumento de miopía. En 2019, establecieron un horario límite (desde las 22:00 a las 08:00 h no se podía jugar online); restringiendo a 90 minutos la conexión durante la semana y a 3 horas los festivos y fines de semana. Compañías como Tencent limitaron el tiempo de juego 1 hora al día para jugadores menores de 12 años y a 2 horas al día para usuarios de entre 12 y 18 . Medida similar adoptó el juego Fortnite (también en China), que emitía advertencias a los usuarios que llevaban demasiado tiempo jugando (más de 3 horas) para que se desconectasen, llegando incluso a eliminar determinados logros o progresos en caso de no acceder a tales recomendaciones. 


\subsubsection{Publicidad y anuncio de juegos de azar}

El Código de Conducta sobre Comunicaciones Comerciales de las Actividades de Juego desglosa una serie de normas éticas que también deberían tener aplicación en las loot boxes. Sin embargo, con la excepción de los principios generales como el de legalidad (que se ajuste a la normativa vigente) o el de lealtad (exigencia de buena fe y buenos usos mercantiles), que entendemos que se cumplen, desde nuestro punto de vista existen otros no menos importantes, que serían vulnerados por las dinámicas de las cajas botín. En primer lugar, el principio de identificación expone que las comunicaciones comerciales deben ser fácilmente identificables y reconocibles como tales; el principio de veracidad mantiene que estas no deben ser susceptibles de inducir a error y tampoco omitir o silenciar datos sustanciales 0 hechos relevantes si ello induce a error; al tiempo que deben incluir los elementos esenciales que afecten a las eventuales ganancias.

En nuestro ámbito de estudio, la población que juega invirtiendo dinero en conseguir mejoras mediante las loot boxes es desconocedora, en muchos videojuegos, de la probabilidad que existe de obtener el ítem deseado, dado que no aparece reflejado en ningún lugar. Es importante tener presente que, aunque las cajas botín se presentan como aleatorias, todo parece apuntar a un mecanismo más bien probabilístico. Tanto es así que, en aquellos países en los que las loot boxes se encuentran reguladas, se ha obligado a las empresas a publicar sus ratios de probabilidad. Por ejemplo, Blizzard (2018), tras la modificación de la ley de juego en China, reveló las ratios de obtención de sus artículos «aleatorios», a saber: un $20 \%$ de probabilidades de que toque una carta épica en los sobres y un $5 \%$ de legendaria. Aunque es probable que estos datos subyazcan a la probabilidad asociada a las loot boxes en todos los artículos de esta compañía en el mundo, solo se encontraron explicitados en el momento de realización de este trabajo en la web china de Blizzard. Tras la comunicación de estos datos por parte de varias compañías, se observó que los ítems más apreciados llegan a presentar una probabilidad del $0,05 \%$ en juegos con más de 100.000 .000 de jugadores. En otras palabras, la probabilidad de obtener un ítem valioso es de uno cada 13,5 intentos (Hidalgo, 2019). De tal manera, el jugador deberá comprar numerosas loot boxes para obtener el artículo que anhela (King y Delfabbro, 2018). Si bien es verdad que en España, al no estar reguladas las cajas botín como juegos de azar, no se encuentran sujetas a la obligatoriedad de publicar el porcentaje de probabilidades de obtención -tal como recoge el Real Decreto 2110/1998-, es cuanto menos peligroso que los menores (y la mayoría de los progenitores) puedan tener acceso a su consumo sin contar con la suficiente información.

Por otra parte, los principios de juego responsable descritos en el Código de Conducta señalan en el punto 6.8 , la prohibición de

Si bien es verdad que en España, al no estar reguladas las cajas botín como juegos de azar, no se encuentran sujetas a la obligatoriedad de publicar el porcentaje de probabilidades de obtención, es cuanto menos peligroso que los menores puedan tener acceso a su consumo sin contar con la suficiente información 
inducir a error sobre la posibilidad de resultar premiado y de dar a entender que la repetición del juego aumenta la probabilidad de ganar. Pese a que no se puede afirmar que las loot boxes cometan ilícito, cuando los progenitores responsables adquieren un juego basándose en las indicaciones sobre la adecuación de edad y contenido (PEGI) entienden que, bajo unos límites adecuados, el entretenimiento no entraña riesgos. No obstante, la cuestión se vuelve perversa cuando se permite, al menos en cuanto a calificación, el acceso a dinámicas que utilizan ardides psicológicos que pueden causar adicción.

Otros principios igualmente relevantes son el 6.9, sobre la prohibición de sugerir que la habilidad o la experiencia eliminan el azar; el 6.11, sobre la prohibición de asociar situaciones de juego repetitivas a emociones fuertes; la obligatoriedad de plasmar la advertencia sobre juego responsable; la prohibición de jugar a los menores de 18 años, no incluyendo la presencia de deportistas en activo realizando actividades de juego o aconsejándolas. En el apartado 7 se recogen las indicaciones específicas para la protección de menores, entre ellas, que no se utilice a menores, ni siquiera menores de 25 años para los comerciales, que no se explote la relación de confianza que los menores depositan en progenitores, docentes, etc., o cualquier persona que ostente notoriedad pública y participe en espacios infantiles; resaltando, en el punto 7.3, que no se empleen elementos visuales, sonoros, verbales o escritos que sean especialmente dirigidos a menores, o en su caso, con una advertencia de «ficción publicitaria».

Todos estos principios parecen vulnerarse en el caso de las loot boxes en relación con la figura del creador de contenido. Estos jugadores, que suelen ser muy jóvenes, producen vídeos de gran calidad audiovisual en los que aparecen invirtiendo cuantiosas sumas en la apertura de estas cajas, en muchas ocasiones de modo patrocinado. Su poderosa influencia en la formación de opiniones podría ser un elemento a tener en cuenta en la valoración de la licitud de este comportamiento. Finalmente, los principios sobre horarios de publicidad establecen que los comerciales tipo Ruleta, Black Jack, Póker, etc., solo podrán emitirse entre las 22:00 y las 06:00 h, y no en espacios televisivos o radiofónicos destinados a población infantil. En este caso, las cajas botín tampoco se ajustan a este indicador, en tanto que su única publicidad suele ser la que reciben de los creadores de contenido. De este modo, se encontrarán disponibles en todo momento en los vídeos de plataformas online, no pudiendo restringirse su horario de difusión.

\subsubsection{Noticias relacionadas con el consumo abusivo de loot boxes}

Como hemos visto, en nuestro país, la normativa existente no contempla la realidad de las loot boxes, lo que supone una dificultad añadida a su tratamiento. Sin embargo, la ausencia de marcos normativos relativos a este fenómeno no significa que no den lugar a situaciones de consumo problemático. 
A continuación, ante la carencia de antecedentes jurídicos, se exponen algunos casos que han atraído la atención mediática y que muestran la magnitud de las consecuencias del consumo abusivo de las cajas botín:

- «Un adolescente gasta 3.000 libras en loot boxes de FIFA20». Un adolescente inglés confesó a la BBC que había gastado todos sus ahorros para ir a la universidad en personajes de FIFA20 (BBC News, julio de 2020).

- «Cuatro niños gastan cerca de 550 libras en tres semanas comprando packs de jugadores de FIFA en la cuenta familiar de Nintendo Switch». Se daba voz a un padre que había regalado a sus hijos un pack de jugadores de este videojuego valorado en 8 libras, olvidando retirar la tarjeta de la plataforma. Los hijos, todos menores de 10 años, adquirieron numerosos packs de personajes tratando de conseguir a Messi. Tras la denuncia, Nintendo se comprometió a reintegrar el gasto a la familia (BBC News, julio de 2019).

- «Un chico gasta más de 1.000 libras de su madre en Fortnite». En Reino Unido, una madre denunció que su hijo de 10 años había introducido los datos de su tarjeta bancaria sin permiso, gastando 1.193 libras (LadBiblie.com, septiembre de 2018).

- «Una madre de Cork advierte de las loot boxes después de que su hijo de 14 años gastara todo el sueldo de la familia en FIFA18» (Irish Mirror, diciembre de 2017).

- «Un padre: "Mi hijo adolescente gastó 4.500 dólares en microtransacciones en FIFA"» (CinemaBlend, marzo de 2015).

- «Un niño de 11 años gasta accidentalmente 7.500 dólares en microtransacciones usando la tarjeta de crédito de su padre» (TechSpot.com, abril de 2017).

Existen más ejemplos en la prensa de casos similares, pero todos ellos ponen de manifiesto la facilidad que tienen los menores para acceder y adquirir estos contenidos, reflejando no solo los problemas económicos ocasionados, sino también la pérdida conductual que producen. En este sentido, todas las noticias comparten el mismo inicio: los progenitores permiten una única compra de escaso valor, pero a esta le sigue la necesidad psicológica de buscar el ítem deseado que se traduce en compras repetidas en un corto espacio de tiempo. Así, las loot boxes parecen tener un componente en su presentación que facilita la pérdida de control del individuo, algo que no se observa en la adquisición de otros productos dentro de los videojuegos en los que la persona es conocedora del contenido exacto. La incertidumbre y la aleatoriedad parecen ser dos características que dificultan el control sobre el comportamiento, lo que trae aparejado gran malestar psicológico en los menores.

La incertidumbre y la aleatoriedad
parecen ser dos características
que dificultan el control sobre
el comportamiento, lo que
trae aparejado gran malestar
psicológico en los menores 


\section{Juego sostenible. El papel de la familia y el profesorado}

Las cajas botín se han establecido como una estrategia recurrente dentro de los videojuegos; un producto de fácil acceso, especialmente para los menores. La dificultad para regular adecuadamente estas dinámicas y poner fin a las situaciones de riesgo en el espacio virtual nos lleva a plantear la necesidad de diseñar modelos basados en la educación (tanto para niñez y adolescencia como para las familias). Aunque es evidente que se ha producido un notable incremento del consumo de contenidos digitales y del uso de las TIC (Garmendia et al., 2016), estos datos deben ser tomados con cautela, entendiendo que, si se han instaurado como un elemento fundamental de nuestro día a día, en el caso de los más jóvenes, constituyen una extensión natural de su mundo. Así, ante la aparente hiperdigitalización de la sociedad, hemos de adoptar una postura empática y, sobre todo, contextualizada, ya que los nuevos modelos de socialización e interacción de los nativos digitales pueden incentivar un uso intensivo de las TIC, el cual podría alejarse de la utilización de carácter más funcional que hacen las generaciones anteriores. La brecha digital intergeneracional puede llevar a patologizar conductas normativas dentro del contexto sociocultural actual, etiquetando como adicción el uso intensivo. La interpretación contextualizada de la realidad es importante por sus implicaciones prácticas y asistenciales. Atendiendo a todo lo expuesto sobre los hábitos de consumo de ocio digital (por ejemplo, apuestas, videojuegos, etc.), consideramos que es fundamental dirigir las medidas educativas y terapéuticas hacia un paradigma basado en el empoderamiento frente al modelo más tradicional vinculado a la patologización. En este sentido, si nos basamos en los datos que advierten de la elevada implicación de los jóvenes en los juegos de azar online y en las loot boxes, es importante que tratemos de darles herramientas y recursos para que, en caso de querer hacer uso de ellos, se haga de manera crítica, responsable y sostenible.

Los principios que subyacen a este argumento son sencillos. Primero, las TIC no van a desaparecer, ni tampoco lo harán los juegos de azar. La facilidad con la que se han aunado ambos hace prácticamente imposible su reversibilidad. Adicionalmente, la regulación se ha mostrado incapaz de cubrir todos los aspectos legislativos que garantizan la protección total de los menores, de modo que es necesario proporcionarles estrategias y herramientas para enfrentarse a estas amenazas con éxito. Segundo, considerar el uso intensivo de las TIC y las formas de juego online sistemáticamente como problemáticas puede dar lugar a reactancia psicológica, esto es, una resistencia conductual que lleva a sobreproducir la conducta que se trata de reducir. Esta cuestión, unida a la normalización del consumo digital, la relativización del riesgo del comportamiento online y la confluencia de numerosos sesgos cognitivos asociados al azar (por ejemplo, ilusión de invulnerabilidad, percepción de control, etc.), hacen que sea, de nuevo, fundamental capacitar a los menores para actuar de modo responsable. 
Con todo, se trata de un fenómeno reciente del que apenas existe cuerpo teórico que nos permita desarrollar estrategias efectivas basadas en la evidencia. Así, con el objeto de dotar a las familias y al profesorado de recursos para dar respuesta a este tipo de comportamientos, se proponen recomendaciones y pautas de actuación dirigidas a la identificación temprana de factores de riesgo relativos al juego online y, concretamente, al consumo de loot boxes. En todos los contextos en los que se trabaja con menores es imperativo que exista una relación fluida entre el centro y la familia, de manera que puedan llevarse a cabo actuaciones coordinadas. En el caso de las loot boxes se antoja especialmente relevante, puesto que se trata de un fenómeno de difícil identificación en el ámbito educativo y que puede dar lugar a consecuencias que se encuentran presentes en muchas otras casuísticas (por ejemplo, acoso escolar). El fin de estas recomendaciones es visibilizar este fenómeno, poco conocido y, a priori, inocuo, para generar medidas preventivas efectivas.

\subsection{Pautas y recomendaciones para las familias}

Descubrir que los hijos se encuentran en una situación de riesgo puede ser una experiencia compleja para las familias, no solo por tomar conciencia del sufrimiento del menor, sino también por la dificultad para dar respuesta a una experiencia nueva y desconocida. Por ello, lo primero es comprender en qué consiste el consumo de loot boxes, seguido de la identificación de indicios de la existencia del problema y, finalmente, estrategias de actuación aplicables tras la detección.

\subsubsection{Detección: señales de alarma ante las microtransacciones y las loot boxes}

En la mayor parte de los casos, los menores cuentan con el permiso de la familia para la adquisición de las loot boxes, dado que su compra requiere la introducción de una tarjeta bancaria. Así, se recomienda que estos se encuentren presentes en el momento de la compra y que observen la conducta del menor por si aparece alguna de las siguientes señales:

- Las loot boxes son un tema de conversación recurrente (por ejemplo, artículos que les han tocado, dinero invertido, etc.) y el menor manifiesta preocupación constante por las skins u otros artículos aleatorios dentro del videojuego.

- Se entusiasma con los creadores de contenido (por ejemplo, youtubers), especialmente, con quienes gastan una cantidad sustancial de dinero en estos artículos aleatorios.

- Vive la apertura de las cajas con intensidad, mostrando reacciones emocionales extremas (euforia con el artículo que deseaba o episodios de ira o tristeza desmesurada si no consigue lo que quería). 
- Planea y evalúa estrategias antes de la compra para optimizar los resultados (por ejemplo, elige los mejores sobres, busca webs que den más ganancias, etc.). O ha intentado comprar solo una loot box, pero no ha podido parar. Tras abrirla, manifiesta la necesidad de seguir comprando cajas.

- Invierte el dinero que recibe (cumpleaños, paga, etc.) en contenidos de videojuego, tarjetas prepago de tiendas virtuales, skins, loot boxes, contenidos descargables (DLC), etc. Aumenta progresivamente la cantidad de dinero que gasta o la frecuencia de adquisición. Ha intentado reducir la compra por sí mismo, pero no se siente capaz. O ha ocultado/mentido acerca del gasto de las microtransacciones. Ha hecho uso de la tarjeta familiar o de otra persona pese a no contar con su consentimiento.

- Los progenitores han encontrado pequeñas microtransacciones en su tarjeta bancaria (por ejemplo, $1 €$ ) que no reconocen como propias. O su hijo ha recibido un pago por medios externos no justificados (por ejemplo, vendiendo el contenido de la loot box).

- Muestra interés por otras formas de apuestas, como las deportivas, que pueden tener que ver con el videojuego (por ejemplo, webs como FutGoles, Utcoinbet, etc.).

- Los progenitores encuentran a su hijo jugando a altas horas de la madrugada o el menor ha llegado a pasar alguna noche sin dormir por estar jugando, mostrando cansancio y falta de energía por la mañana.

Es importante tener en cuenta que algunas de estas señales pueden aparecer en muchas otras circunstancias (acoso escolar, violencia en el noviazgo, dificultades académicas o incluso ser una parte normativa de la adolescencia). Sin embargo, es necesario prestar atención a todas aquellas contingencias que puedan generar algún tipo de daño psicológico o emocional en los menores debido al impacto que esto tiene en su desarrollo. Por ello, aunque las señales anteriormente descritas no implican necesariamente que exista un problema de juego patológico, pueden ser indicativas de alguna dificultad que es necesario monitorizar.

La identificación de un consumo online de riesgo es de gran complejidad. Primero, por tratarse de una conducta normalizada entre los menores que implica un bajo nivel de pérdidas económicas y que no son consideradas como juegos de azar. Segundo, el menor que experimenta sentimientos negativos tras el consumo de loot boxes puede tratar de gestionar el problema por sí mismo, creyendo que tiene control sobre la situación, relativizando los riesgos y las pérdidas o filtrando únicamente los resultados positivos. En caso de que haya experimentado emociones negativas derivadas de las loot boxes o tome conciencia del problema, puede tratar de ocultar la situación debido a sentimientos de miedo, vergüenza y culpa. Así, ante el descubrimiento de un consumo abusivo, se suelen dar en las familias reacciones emocionales que, aunque comprensibles, no se adecúan a las necesidades inmediatas del menor. Por ello, a continuación, expondremos algunas recomendaciones para las distintas fases del proceso: prevención, detección e intervención temprana. 


\section{Fase 1. Prevención ante las microtransacciones}

- Obtener información sobre los videojuegos previa a su adquisición. Todos los juegos del mercado se clasifican bajo los criterios PEGl, que determinan la edad adecuada de consumo según una serie de indicadores (por ejemplo, lenguaje obsceno, violencia explícita, sexo, etc.). Recientemente, se ha incorporado la categoría "compras" dentro del videojuego o in-game purchases, que permite identificar si el videojuego contiene artículos que pueden ser adquiridos con dinero real.

- Explicar los mecanismos subyacentes a los juegos de azar y cómo estos generan la sensación de necesidad. Es importante que los menores sepan que estas mecánicas no suelen ser aleatorias, sino probabilísticas, es decir, requieren de un número de intentos para obtener los objetos deseados, de manera que es una cuestión de inversión, no de suerte. Por tanto, es mejor comprar un artículo específico que hacerlo de manera aleatoria; si no acabaremos gastando más dinero.

- Conocer a los creadores de contenido que sigue el menor (YouTube, Twitch, etc.), pues pueden ser una forma de entrada a las loot boxes. Es frecuente que estos jugadores creen vídeos en los que invierten una gran cantidad de dinero abriendo estas cajas, lo que normaliza el gasto y motiva la necesidad de emularlos.

- Supervisión del uso de la tecnología. Aunque se debe garantizar la privacidad del menor, también es necesario supervisar su consumo de contenidos digitales. Por ello, se recomienda implementar el control parental (por ejemplo, acceso a webs inadecuadas para su nivel de desarrollo, límite de gasto en aplicaciones, etc.), instando a utilizar los dispositivos electrónicos en zonas comunes.

- Compartir tiempo de juego. Estar al corriente del tipo de videojuego al que juega el menor, incluso probarlo, puede contribuir a mejorar la relación paterno/materno-filial y, además, hará conocer a los padres/madres/tutores el tipo de contenido al que está expuesto.

- Protección económica ante transacciones indeseadas. Para adquirir una loot box es necesario introducir la tarjeta bancaria en la plataforma de compra. Tras la operación, la información de facturación no se elimina automáticamente, sino que queda almacenada en el sistema. De este modo, si olvidamos retirar los datos, será posible realizar nuevas transacciones. Por este motivo, y por otras vulneraciones de seguridad, se recomienda retirar la tarjeta del sistema y, siempre que sea posible, emplear tarjetas prepago con una cantidad de dinero limitada.

Fases 2 y 3. Detección del consumo e intervención temprana

Una vez detectado que el menor pueda tener un consumo de riesgo respecto a estas microtransacciones, siguiendo las señales de alarma, debemos:

- Tratar el tema con normalidad. El consumo de riesgo de juegos de azar produce sentimientos de culpa, miedo o vergüenza que pueden dificultar que se revele la situación. Por ello, es fundamental garantizar un espacio seguro en el que hablar sin juzgar ni estigmatizar la conducta. Manifestar rabia, enfado o culpabilizar puede llevar a que los menores no sientan confianza y oculten en el futuro otras situaciones.

- Elaborar un plan de acción. Como se ha visto, existen casos en los que las loot boxes suponen un perjuicio económico importante para las familias. Aunque una reacción normal puede ser retirar los dispositivos electrónicos al menor y castigarlo, estas conductas no inciden en el problema de base. No es recomendable enjuiciar la conducta o reprochar la incapacidad del menor para detenerse a tiempo, teniendo en cuenta que estos mecanismos están diseñados para generar necesidad de consumo. Al igual 
que cualquier otro tipo de adicción, cambiar la conducta es un proceso y requiere tiempo. El trabajo con la familia para instaurar modelos de consumo digital sano es primordial, centrándose en el menor si las medidas aplicadas no son efectivas o si la conducta de juego/consumo problemático presenta una gravedad significativa. Siempre que sea posible, y cuando el nivel de afectación no sea severo, se recomienda la intervención en el medio natural del menor.

- Proporcionar alternativas de ocio. Estimular el desarrollo de aficiones diferentes a los videojuegos (por ejemplo, juegos de mesa, deporte, etc.) puede contribuir a adquirir valores útiles para hacer frente a las conductas de riesgo. Además, si estas actividades se hacen en familia, contribuirán a fortalecer vínculos, comunicación y confianza.

Fuente: elaboración propia.

\subsection{Pautas y recomendaciones para el profesorado}

Desde el contexto educativo se proponen recomendaciones orientadas a la prevención de consumos de riesgo. Dado que se trata de un contexto fundamental en el desarrollo y socialización de los menores, en el que pasan la mayor parte de su tiempo, tratar problemáticas psicosociales que afectan a su salud y bienestar en el currículo académico es prioritario. Las pautas descritas pueden aplicarse en todos los contextos educativos con adaptaciones según el nivel de desarrollo cognitivo y socioafectivo del alumnado. Se recomienda, en la medida de lo posible, que las intervenciones se desarrollen como proceso en lugar de actuaciones específicas, en tanto que se consideran más efectivas. Desde este modelo, se insta a introducir estos conceptos de modo transversal en el currículo académico, complementándose con otras medidas más puntuales, como talleres.

\subsubsection{Prevención primaria}

Inicialmente, se recomienda implementar medidas para prevenir el consumo problemático con actividades dirigidas a todo el alumnado para trabajar los aspectos más relevantes de los juegos de azar, incluyendo las loot boxes de manera específica. Desde la perspectiva de proceso y transversalidad, se recomienda introducir conceptos vinculados al consumo de juegos de azar en las diferentes asignaturas. Por ejemplo, en matemáticas es posible introducir los mecanismos del juego de azar cuando se explican las probabilidades. La psicoeducación debe acompañarse, necesariamente, de acciones orientadas al desarrollo y a la potenciación de recursos personales que permitan hacer frente a los consumos de riesgo. Así, de modo complementario a los contenidos de juegos de azar, microtransacciones y cajas botín, se recomienda trabajar las siguientes habilidades: 
- Autoestima. El consumo de loot boxes se ha descrito como un modo de obtener reconocimiento por parte de los iguales y de integración (King et al., 2020). El objetivo de este módulo es que el alumnado desarrolle un autoconcepto positivo que le lleve a la aceptación incondicional de sí mismo, de modo que su valor no venga determinado por aspectos como poseer artículos apreciados por el grupo. De esta manera, no contar con las skins más prestigiosas o no haber invertido sumas de dinero en cajas no sería un elemento relevante en el bienestar del menor.

- Asertividad. Dada la importancia que se confiere a la opinión de las amistades en esta etapa del desarrollo, es frecuente que muchas de las conductas desadaptativas o de riesgo tengan como origen la aceptación de los pares. La asertividad es una habilidad básica para proteger los propios derechos, opiniones y necesidades frente a las presiones externas. A través de esta capacidad, seremos menos vulnerables a la necesidad psicológica de compra que producen las loot boxes.

- Comunicación. En esta etapa, la autosuficiencia es altamente valorada, por ello, es habitual que los estudiantes, ante una situación adversa, traten de solucionarla por sí mismos. Es importante generar un espacio seguro, de manera que sean conscientes de que tienen una persona a la que acudir si se encuentran en dificultades. El profesorado puede ser esta figura, puesto que pasan gran cantidad de tiempo con ellos y la comunicación de situaciones estresantes puede tener un menor impacto emocional que hacerlo con la familia.

- Estrategias de afrontamiento. La búsqueda de autonomía propia de la adolescencia, junto con los sesgos de pensamiento que se producen en esta etapa («nadie me entiende», «estoy solo», etc.) llevan a que se empleen, asiduamente, estrategias desadaptativas para resolver los problemas (por ejemplo, consumo de sustancias para no pensar, autolesiones, etc.). Ayudarlos a que sean capaces de desarrollar planes de acción que les garanticen soluciones positivas se revela como medida de protección frente a consumos de riesgo. En el caso de las loot boxes, hemos visto antecedentes jurídicos en los que se describen grandes gastos. La ocultación de la verdad por parte de los menores en un intento por reducir el castigo puede llevar a una bola de nieve que dé lugar a peores efectos. Un clima familiar afectivo tiene un gran impacto en todas las esferas de la vida del menor (Capo, 2011).

\subsubsection{Prevención secundaria}

Las actuaciones irán destinadas al alumnado en riesgo de comprar loot boxes, teniendo en cuenta el número de horas y los videojuegos a los que más tiempo dedican. Se abordarán los aspectos de la prevención primaria, pero de forma más específica, favoreciendo 
que se haga un uso responsable de los juegos de azar. Si entre el alumnado encontramos estudiantes que hayan adquirido estos artículos aleatorios y su consumo no es problemático, podríamos optar por proporcionar pautas de prevención basadas en un consumo sostenible. Por contra, si manifiesta algunas de las señales de alarma expuestas previamente, se debería advertir a la familia y derivar el caso a profesionales especializados en esta problemática.

Atendiendo al concepto de «escuela global», todas las medidas dirigidas a potenciar el desarrollo del alumnado requieren, necesariamente, de una relación sólida entre todos los agentes de socialización de los menores, siendo de especial relevancia la familia y la escuela, pero sin olvidar la influencia de otros actores sociales como son los recursos comunitarios. Así, proponemos que además de la aplicación de estas pautas en los distintos contextos, se realicen actividades conjuntas en las que se dote a las familias y al profesorado de herramientas para prevenir e intervenir adecuadamente en estos casos (talleres para padres y madres, sesiones de formación para el profesorado, sesiones de convivencia).

\section{Conclusiones}

Hemos presentado el fenómeno de las loot boxes desde diferentes ópticas, dibujando el perfil de este mecanismo que, si bien es cada vez más frecuente en los videojuegos, suele ser desconocido para los progenitores y educadores. Aunque la literatura es todavía incipiente, parece indicar que las cajas botín, por sus características, pudieran ser un factor predisponente al consumo de otros juegos de azar, exponiendo a los menores a una situación de vulnerabilidad. Además, la mayor parte de las medidas establecidas para regular el uso abusivo de la tecnología en los menores adoptan con frecuencia un enfoque punitivo en el que se demoniza su utilización. Sin embargo, las TIC constituyen un elemento fundamental en nuestra sociedad, por lo que es importante que se produzca un cambio de paradigma en el modo en que se tratan las conductas de consumo intensivo, e incluso problemático, alejándonos del modelo biomédico tradicional de corte patologizador, para abogar por empoderar al usuario y dotarlo de estrategias para hacer un uso responsable y sostenible de los contenidos digitales, ya que ni la tecnología ni los juegos de azar van a desaparecer.

Proponemos pues, una perspectiva psicoeducativa en la que se proporcione a la adolescencia, como usuarios diana de este tipo de productos virtuales, estrategias y recursos para hacer frente de manera efectiva a los riesgos que entrañan. Así, el uso que los menores hacen de estos artículos debería ser educado, instando a un consumo crítico y responsable desde el prisma de la prevención, supervisando el contenido de estos artículos azarosos y el momento de la apertura. 


\section{Referencias bibliográficas}

Abarbanel, B. (2018). Gambling vs. gaming: a commentary on the role of regulatory, industry, and community stakeholders in the loot box debate. Gaming Law Review, 22(4), 231-234. https://doi.org/10.1089/glr2.2018. 2243

AEVI. (2018). La industria del videojuego en España. Anuario 2018. http://www.aevi.org. es/web/wp-content/uploads/2019/05/AEVI_ Anuario_2018.pdf

AEVI. (2019). La industria del videojuego en España: Anuario 2019. http://www.aevi.org. es/web/wp-content/uploads/2020/04/Anua rio-AEVI-2019.pdf

Blizzard. (2018). Anuncio sobre la probabilidad de extracción de suministros de "Overwatch». https://ow.blizzard.cn/article/ news/486

Brady, A. y Prentice, G. (2019). Are loot boxes addictive? Analyzing participant's physiological arousal while opening a loot box. Games and Culture, 16(4), 419-433. https://doi.org/ $10.1177 / 1555412019895359$

Brooks, G. A. y Clark, L. (2019). Associations between loot box use, problematic gaming and gambling, and gambling-related cognitions. Addictive Behaviors, 96, 26-34. https:// doi.org/10.1016/j.addbeh.2019.04.009

Capo Bauzá, M. ${ }^{a}$ C. (2011). Mis hijos y las drogas: la prevención a través del clima familiar afectivo. Guía para padres. Ediciones de la $U$.

Derevensky, J. L. y Griffiths, M. D. (2019). Convergence between gambling and gaming: does the gambling and gaming industry have a responsibility in protecting the consumer? Gaming Law Review, 23(9), 633-639. https://doi.org/10.1089/glr2.2019.2397

Drummond, A. y Sauer, J. D. (2018). Videogame loot boxes are psychologically akin to gambling. Nature Human Behaviour, 2, 530-532. https://doi.org/10.1038/s41562-0 18-0360-1
Drummond, A., Sauer, J. D., Ferguson, C. J. y Hall, L. C. (2020). The relationship between problem gambling, excessive gaming, psychological distress, and spending on loot boxes in Aotearoa New Zealand, Australia, and the United States-A cross-national survey. PLOS ONE, 15(3). https://doi.org/ 10.1371/journal.pone.0230378

Drummond, A., Sauer, J. D. y Hall, L. C. (2019). Loot box limit-setting: a potential policy to protect video game users with gambling problems? Addiction, 114(5), 935-936. https:// doi.org/10.1111/add.14583

Dye, M., Green, C. y Bavelier, D. (2010). The development of attention skills in action video game players. Neuropsychologia, 47(8-9), 1.780-1.789. https://doi.org/10.1016/j.neu ropsychologia.2009.02.002

Echeburúa, E. (1999). ¿Adicciones... sin drogas? Las nuevas adicciones: juego, sexo, comida, compras, internet, trabajo... Editorial Desclée.

Eguia Gómez, J. L., Contreras-Espinosa, R. S. y Solano-Albajes, L. (2013). Videojuegos: conceptos, historia y su potencial como herramienta para la educación. 3c TIC: Cuadernos de Desarrollo Aplicados a las TIC, 1(2), 1-14.

Entertaiment Software Association. (2018). 2019 Essential Facts About the Computer and Video Game Industry. https://www.theesa.com/ resource/essential-facts-about-the-compu ter-and-video-game-industry-2019

Gainsbury, S. M. (2019). Gaming-gambling convergence: research, regulation, and reactions. Gaming Law Review, 23(2), 80-83. https://doi.org/10.1089/glr2.2019.2323

Garmendia Larrañaga, M. Jiménez Iglesias, E., Casado, M. A. y Mascheroni, G. (2016). Net Children Go Mobile: riesgos y oportunidades en internet y el uso de dispositivos móviles entre menores españoles (2010-2015). Red. es; Universidad del País Vasco.

Gil Irazo, R. M. ${ }^{a}$, Arnedo-Moreno, J., González, C. S., Paderewski, P., Domenech, M. y Lleras 
de Frutos, M. ${ }^{a}$ (2020). Generación Z y Fortnite: lo que engancha a los más pequeños. Revista Digital de AIPO (Asociación Interacción Persona-Ordenador), 1, 32-42.

Greenberg, B. S., Sherry, J., Lachlan, K., Lucas, K. y Holmstrom, A. (2010). Orientations to video games among gender and age. Simulation \& Gaming, 41(2), 238-259. https://doi. org/10.1177/1046878108319930

Greitemeyer, T. y Mügge, D. O. (2014). Video games do affect social outcomes: a metaanalytic review of the effects of violent and prosocial video game play. Personality and Social Psychology Bulletin, 40(5), 578-589. https://doi.rg/10.1177/0146167213520459

Griffiths, M. D. (1995). Technological addictions. Clinical Psychology Forum, 76, 14-19.

Griffiths, M. D. (2018). Is the buying of loot boxes in video games a form of gambling or gaming? Gaming Law Review, 22(1), 52-54. https://doi.org/10.1089/glr2.2018.2216

Griffiths, M. y Beranuy, M. (2009). Adicción a los videojuegos: una breve revisión psicológica. Revista de Psicoterapia, 19(73), 33-49.

Hernández Ortega, J. (2019). Representaciones transmedia en entornos de lectura analógica. Tecnología, Ciencia y Educación, 14, 5-36. https://doi.org/10.51302/tce.2019.329

Hidalgo, A. (2019). Loot boxes: juegos de azar encubiertos al alcance de menores. Revista Jurídica de Castilla y León, 47, 25-58.

Holtz, P. y Appel, M. (2011). Internet use and video gaming predict problem behavior in early adolescence. Journal of Adolescence, 34(1), 49-58. https://doi.org/10.1016/j.ado lescence.2010.02.004

INE. (2019). Encuesta sobre equipamiento y uso de tecnologías de información y comunicación en los hogares. https://www.ine.es/ prensa/tich_2019.pdf

Interactive Software Federation of Europe. (2017). GameTrack European Summary Data. https://www.isfe.eu/wp-content/uploads/ 2019/01/gametrack_european_summary_ data_2017_q4.pdf

King, D. L. y Delfabbro, P. H. (2018). Predatory monetization schemes in video games (e. g., «loot boxes») and internet gaming disorder. Addiction, 113(11), 1.967-1.969. https://doi. org/10.1111/add.14286

King, D. L. y Delfabbro, P. H. (2019a). Loot box limit-setting is not sufficient on its own to prevent players from overspending: a reply to Drummond, Sauer \& Hall. Addiction, 114(7), 1.324-1.325. https://doi.org/10.1111/ add.14628

King, D. L. y Delfabbro, P. H. (2019b). Video game monetization (e. g., «loot boxes»): a blueprint for practical social responsibility measures. International Journal of Mental Health and Addiction, 17(1), 166-179. https:// doi.org/10.1007/s11469-018-0009-3

King, D. L., Russell, A. M. T., Delfabbro, P. H. y Polisena, D. (2020). Fortnite microtransaction spending was associated with peers' purchasing behaviors but not gaming disorder symptoms. Addictive Behaviors, 104. https:// doi.org/10.1016/j.addbeh.2020.106311

Kristiansen, S. y Severin, M. C. (2020). Loot box engagement and problem gambling among adolescent gamers: findings from a national survey. Addictive Behaviors, 103. https://doi. org/10.1016/j.addbeh.2019.106254

Labrador, F. J. (2013). La importancia de los factores cognitivos en la adicción al juego. En M. ${ }^{a}$ T. Laespada y A. Estevez (Eds.), ¿Existen las adicciones sin sustancias? Serie Drogodependencias (vol. 29, p. 39). Instituto Deusto de Drogodependencias.

Larche, C. J., Chini, K., Lee, C., Dixon, M. J. y Fernandes, M. (2019). Rare loot box rewards trigger larger arousal and reward responses, and greater urge to open more loot boxes. Journal of Gambling Studies. https://doi. org/10.1007/s10899-019-09913-5

Ledo Rubio, A. I., Gándara Martín, J. J. de la, García Alonso, M. ${ }^{a}$ I. y Gordo Seco, R. (2016). Videojuegos y salud mental: de laadicción a la rehabilitación. Cuadernos de Medicina Psicosomática y Psiquiatría de Enlace, $117,72-83$

Lemmens, J.S. y Hendriks, S. J.F.(2016). Addictive online games: examining the relationship between game genres and internet gaming disorder. Cyberpsychology, Behavior, and Social 
Networking, 19(4), 270-276. https://doi.org/ 10.1089/cyber.2015.0415

Lenhart, A. (2015). Chapter 3: video games are key elements in friendships for many boys. Pew Research Center: Teens, Technology and Friendships. https://www.pewresearch. org/internet/2015/08/06/chapter-3-videogames

León Jariego, R. y López López, M.ª J. (2003). Los adolescentes y los videojuegos. Apuntes de Psicología, 21(1), 1-10.

Ley 13/2011, de 27 de mayo, de regulación del juego (Boletín Oficial del Estado [BOE] núm. 127, de 28 de mayo de 2011).

Li, W., Mills, D. y Nower, L. (2019). The relationship of loot box purchases to problem video gaming and problem gambling. Addictive Behaviors, 97, 27-34. https://doi. org/10.1016/j.addbeh.2019.05.016

López-Fernández, F., Mezquita, L., Griffiths, M., Ortet, G. y lbáñez, M. (2020). El papel de la personalidad en el juego problemático y preferencias de géneros de videojuegos en adolescentes. Adicciones. https://www. adicciones.es/index.php/adicciones/article/ view/1370

Macey, J. y Hamari, J. (2019). eSports, skins, and loot boxes: participants, practices and problematic behaviour associated with emergent forms of gambling. New Media and Society, 21(1), 20-41. https://doi.org/10. 1177/1461444818786216

Marín Díaz, V. y García Fernández, M. a D. (2005). Los videojuegos y su capacidad didácticoformativa. Pixel-Bit. Revista de Medios y Educación, 26, 113-119.

McCaffrey, M. (2019). The macro problem of microtransactions: the self-regulatory challenges of video game loot boxes. Business Horizons, 62(4), 483-495.

McDermott, A. F., Bavelier, D. y Green, C. S. (2014). Memory abilities in action video game players. Computers in Human Behavior, 34, 69-78. https://doi.org/10.1016/j.chb.2014. 01.018

Meduna, M., Steinmetz, F., Ante, L., Reynolds, J. y Fiedler, I. (2019). Loot boxes-a game changer? Gambling Research Division, 2, 1-14. https://www.researchgate.net/publica tion/331935977_Loot_Boxes_-_A_Game_ Changer

Megías, I. (2020). Jóvenes, juegos de azar y apuestas. Una aproximación cualitativa. Centro Reina Sofía sobre Adolescencia y Juventud; Fundación de Ayuda contra la Drogadicción (FAD). http://doi.org/10.5281/zenodo. 3601078

Mendizábal Vázquez, P. de. (2018). Cajas botín o «loot boxes»: ¿necesidad de regulación como juego de azar? https://www.legaltoday. com/opinion/blogs/nuevas-tecnologiasblogs/blog-prodat/cajas-botin-o-loot-boxesnecesidad-de-regulacion-como-juego-deazar-2018-06-07/

Moral Pérez, M. ${ }^{a}$ E. del y Guzmán Duque, A. P. (2016). Jugar en red social: ¿adicción digital versus comunicación e interacción en CityVille? Cuadernos.Info, 38, 217-231. https:// doi.org/10.7764/cdi.38.810

Moral-Pérez, M. E. del, Fernández García, L. C. y Guzmán Duque, A. P. (2015). Videojuegos: incentivos multisensoriales potenciadores de inteligencias múltiples en educación primaria. Electronic Journal of Research in Educational Psychology, 13(2), 243-270. https:// doi.org/10.14204/ejrep.36.14091

Neely, E. L. (2019). Come for the game, stay for the cash grab: the ethics of loot boxes, microtransactions, and freemium games. Games and Culture, 16(2), 228-247. https:// doi.org/10.1177/1555412019887658

OEI y Fundación Telefónica. (2018). Estudio sobre inclusión de TIC en centros educativos de aulas Fundación Telefónica. Instituto de Evaluación (IESME) de la OEI.

Parong, J., Mayer, R. E., Fiorella, L., MacNamara, A., Homer, B. D. y Plass, J. L. (2017). Learning executive function skills by playing focused video games. Contemporary Educational Psychology, 51, 141-151. https:// doi.org/10.1016/j.cedpsych.2017.07.002

Plass, J. L., O'Keefe, P. A., Homer, B. D., Case, J., Hayward, E. O., Stein, M. y Perlin, K. (2013). The impact of individual, competitive, and collaborative mathematics game play on 
learning and motivation. Journal of Educational Psychology, 105(4), 1.050-1.066. https:// doi.org/10.1037/a0032688

Protégeles. (2005). Videojuegos, menores y responsabilidad de los padres. http://ibdigital. uib.es/greenstone/collect/portal_social/ index/assoc/ cmadrid0007.pdf

Ricoy, M. C. y Ameneiros, A. (2016). Preferencias, dedicación y problemáticas generadas por los videojuegos: una perspectiva de género. Revista Complutense de Educación, 27(3), 1.291-1.308. https://doi.org/10.5209/ rev_RCED.2016.v27.n3.48445

Ruiz-Ariza, A., López-Serrano, S., Suárez-Manzano, S. y Martínez-López, E. J. (2018). Videojuegos activos y cognición. Propuestas educativas en adolescentes. RIED. Revista Iberoamericana de Educación a Distancia, 21(2), 285-303. http://dx.doi.org/10.5944/ ried.21.2.19799

Sánchez-Rodríguez, P., Alfageme González, M. y Serrano Pastor, F. (2010). Aspectos sociales de los videojuegos. RELATEC. Revista Latinoamericana de Tecnología Educativa, 9(1), 43-52.

Sanz, C. (2018). ¿Deberían las cajas de botín dentro de los videojuegos ser ilegales? www.legaltoday.com/blogs/transversal/ comunicando-el-derecho-regulando-lacomunicacion/deberian-las-cajas-de-botindentro-de-los-videojuegos-ser-ilegales

Schwartz, L. (2006). Fantasy, realism, and the other in recent video games. Space and Culture, 9(3), 313-325. https://doi. org/10.1177/1206331206289019

Torrens Mèlich, M. (2008). Patología dual: situación actual y retos de futuro. Adicciones, 20(4), 315-320. https://doi.org/10.20882/adic ciones. 255

UNICEF. (2017). The State of the World's Children 2017. Children in a Digital World. https://www.unicef.org/reports/state-worldschildren-2017

United Kingdom Gambling Commission. (2018). Young People \& Gambling 2018. A Research Study Among 11-16 Year Olds in Great Britain. http://www.theministryofparenting.com/
wp-content/uploads/2018/11/Young-Peo ple-and-Gambling-2018-Report.pdf

Vilanova, N. y Ortega, I. (2017). Generación Z: todo lo que necesitas saber sobre los jóvenes que han dejado viejos a los millennials. Plataforma Editoria.

Villani, D., Carissoli, C., Triberti, S., Marchetti, A., Gilli, G. y Riva, G. (2018). Video games for emotion regulation: a systematic review. Games for Health Journal, 7(2), 85-99. https://doi.org/10.1089/g4h.2017.0108

Vorderer, P., Hartmann, T. y Klimmt, C. (2003). Explaining the enjoyment of playing video games: the role of competition. En D. Marinelli (Ed.), Proceedings of the 2nd International Conference on Entertainment Computing (ICEC 2003). Pittsburgh (pp. 1-8). ACM

Zendle, D. y Bowden-Jones, H. (2019). Loot boxes and the convergence of video games and gambling. The Lancet Psychiatry, 6(9), 724-725. https://doi.org/10.1016/S2215-03 66(19)30285-8

Zendle, D. y Cairns, P. (2018). Video game loot boxes are linked to problem gambling: results of a large-scale survey. PLOS ONE, 14(3). https://doi.org/10.1371/journal. pone.0214167

Zendle, D. y Cairns, P. (2019). Loot boxes are again linked to problem gambling: results of a replication study. PLOS ONE, 14(3). https:// doi.org/10.1371/journal.pone.0213194

Zendle, D., Meyer, R. y Over, H. (2019). Adolescents and loot boxes: links with problem gambling and motivations for purchase. Royal Society Open Science, 6(6). https:// doi.org/10.1098/rsos.190049

Zendle, D., Cairns, P., Barnett, H. y McCall, C. (2020). Paying for loot boxes is linked to problem gambling, regardless of specific features like cash-out and pay-to-win. Computers in Human Behavior, 102, 181-191. https://doi.org/10.31234/osf.io/6e74k

Zendle, D., Meyer, R., Cairns, P. y Ballou, N. (2020). The prevalence of loot boxes in mobile and desktop games. Addiction, 115(9), 1.768-1.772. https://doi.org/10.1111/ add. 14973 